\title{
Simulation of Grid Connected Three-Level Neutral-Point-Clamped qZS Inverter using PSCAD
}

\author{
Carlos Roncero-Clemente (PhD student, University of Extremadura), \\ Enrique Romero-Cadaval (Professor, University of Extremadura), \\ Oleksandr Husev (Research Fellow, Tallinn University of Technology), \\ Dmitri Vinnikov (Principal Research Fellow, Tallinn University of Technology) \\ and Serhii Stepenko (PhD student, Chernihiv State Technological University)
}

\begin{abstract}
This paper is focused on a single-phase three-level neutral-point-clamped quasi-z-source inverter when it is operating being connected to the electrical grid. A control strategy for injecting current synchronized in phase with the voltage at the point of common coupling has been proposed and studied. It is achieved by means of controlling the output voltage between branches adjusting the output current by using a d-q frame and the analysis of the output filter. The control strategy generates the reference to be used in the modulation technique and it has been validated with and without shoot-through switching states. A method to calculate the minimum value of the shoot-through duty cycle is also explained in order to assure the proper control of the injected current when the input voltage is less than peak value of the grid voltage. It is an important feature because 3L-NPC qZSI due to its possibility of boosting input voltage in a single stage would operate better than a traditional inverter, for instance in photovoltaic applications when the value of irradiance is decreased. The presented results have been obtained using PSCAD/EMTDC as a simulation tool.
\end{abstract}

Keywords - Computer simulation, power system simulation, PSCAD, pulse width modulation inverters, voltage control.

\section{INTRODUCTION}

A three-level neutral-point-clamped (3L-NPC) inverter has a lot of advantages, such as lower semiconductor voltage stress, lower required blocking voltage capability, decreased $d v / d t$, better harmonic performance, soft switching possibilities without additional components, higher switching frequency due to lower switching losses and balanced neutralpoint voltage, in comparison with the two-level voltage source inverter. As a drawback it has two additional clamping diodes per phase-leg and more controlled semiconductor switches per branch. The $3 \mathrm{~L}-\mathrm{NPC}$ can normally perform only the voltage buck operation. In order to ensure voltage boost operation an additional DC/DC boost converter should be used in the input stage [1-2].

To obtain buck and boost performance the focus is turned into a quasi-Z-source inverter (qZSI). The qZSI was first introduced in [3]. The qZSI can buck and boost DC-link voltage in a single stage without additional switches.

The qZSI can boost the input voltage by introducing a special shoot-through switching state, which is the simultaneous conduction (cross conduction) of both switches of the same phase leg of the inverter. This switching state is forbidden for traditional voltage source inverters because it causes a short circuit of the DC-link capacitors. Thus, the qZSI has excellent immunity against the cross conduction of top and bottom-side inverter switches. The possibility of using shoot-through eliminates the need for dead-times without having the risk of damaging the inverter circuit. The input voltage is regulated only by adjusting the shoot-through duty cycle. In addition the qZSI has a continuous mode input current (input current never drops to zero), which makes it especially suitable for renewable energy sources (e.g. fuel cells, solar energy, wind energy etc.) [4-11].

A new qZSI topology was proposed and described in [12]. It is a combination of the qZSI and the three-level neutralpoint-clamped (3L-NPC) inverter. The three-level neutralpoint-clamped quasi-z-source inverter (3L-NPC qZSI) has advantages of both of these topologies. It can buck and boost the input voltage, it has short circuit immunity and due to the multilevel topology, high energy density is attainable.

Since the mentioned topology is rather new, in all previous studies the 3L-NPC qZSI was considered as an isolated system [12-15]. The aim of the current work is to develop and study the capabilities of this topology assuming it as connected to the electrical system. A wide range of conditions should be considered (synchronization with the grid voltage, MPPT, anti-islanding methods, reactive power control, etc). This paper is focused on the synchronization of the injected current with the voltage at the point of common coupling (PCC).

Injected current synchronized in phase with the voltage at the PCC has been studied by means of controlling the output voltage between branches. It has been analyzed with and without shoot-through switching states. Also, a method to calculate the minimum value of the shoot-through duty cycle is explained in order to assure the proper control of the injected current. The presented results have been obtained by means of simulation using PSCAD/EMTDC [16] as a simulation tools. This tool is becoming more and more used in research community to develop models and power electrical system studies.

\section{II.3L-NPC QZSI CONNECTED TO THE GRID}

In Fig. 1 we can see the 3L-NPC qZSI connected to the electrical grid, represented it as an ideal voltage source. It means that the electrical grid is considered with a short-circuit power equal to infinite (ideal grid) at the point of common coupling (PCC). 


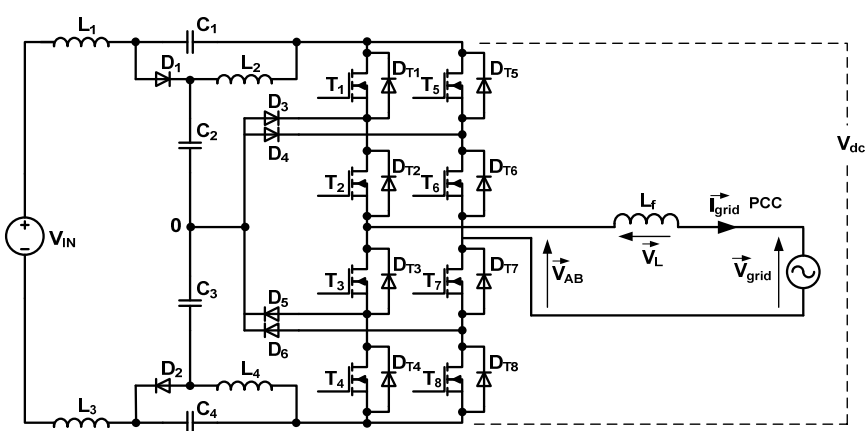

Fig. 1. 3L-NPC qZSI connected to the electrical grid.

TABLE I

RELEVANT VARIABLES INVOLVED IN THE CONTROL STRATEGY

\begin{tabular}{|c|l|}
\hline Variable & \multicolumn{1}{c|}{ Description } \\
\hline$\vec{V}_{A B}$ & $\begin{array}{l}\text { Output voltage phasor of the fundamental component in } \\
\text { terminals of the 3L-NPC qZSI. Voltage between } \\
\text { branches. }\end{array}$ \\
\hline$\vec{V}_{L}$ & Voltage drop phasor in the filter inductance. \\
\hline$\vec{I}_{\text {grid }}$ & Injected current phasor to the grid. \\
\hline$\vec{V}_{\text {grid }}$ & Voltage grid phasor. Voltage at the PCC. \\
\hline
\end{tabular}

To develop the control strategy and generate the reference is necessary to consider the variables defined in Table I. To realize a more precise approach, we will have to take into account the resistance of the filter inductance $\left(R_{f}\right)$. The filter inductance $\left(L_{f}\right)$ is considered as constant to simplify the study.

\section{CONTROL STRATEGy. SYNCHRONIZATION WITH ELECTRICAL GRID}

According to the previous concepts, we can represent the equivalent scheme and the phasor diagram in a $d-q$ frame. The $d$ component of this frame will be synchronized with the voltage at the PCC.

The analyzed point is the connection stage between the converter and the grid by means of an inductor filter to develop the control strategy. Thus, the fundamental component of the reference voltage $\vec{V}_{A B}$ can be generated. Our goal is to generate current in phase with the voltage at the PCC, that is to say, only active power will be injected to the electrical grid.

According to the phasor diagram from Fig.2(b) one has (1):

$$
\vec{V}_{A B}=\vec{V}_{\text {grid }}+\vec{V}_{R}+\vec{V}_{L},
$$

which could be expressed in the $d-q$ frame as (2):

$$
\vec{V}_{A B}=V_{\text {grid }} \cdot \vec{u}_{d}+V_{R} \cdot \vec{u}_{d}+V_{L} \cdot \vec{u}_{q},
$$

where $\vec{u}_{d}$ and $\vec{u}_{d}$ are unitary vector in the $d$ and $q$ directions.

To obtain the unitary vectors, a phase locked loop (PLL) is required. In this work, the PLL available in PSCAD simulation tool library [8] has been used. It generates a ramp signal $(\theta)$ that varies between $0^{\circ}$ and $360^{\circ}$, synchronized or locked in phase, to the instantaneous voltage at the PCC $v_{\text {grid }}(t)$.

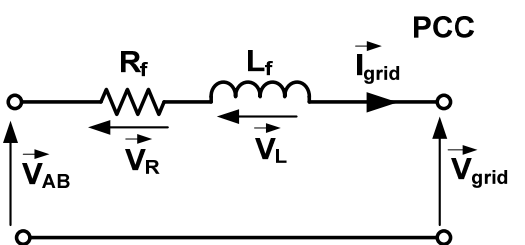

(a)

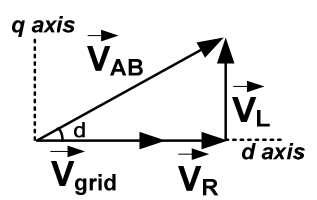

(b)
Fig.2. Equivalent scheme at the PCC (a) and phasor diagram (b).

The RMS value of the $\vec{V}_{A B}$ can be calculated as (3):

$$
V_{A B}=\sqrt{\left(V_{\text {grid }}+V_{R}\right)^{2}+\left(V_{L}\right)^{2}},
$$

where voltages $V_{\text {grid }}, V_{R}$ and $V_{L}$ are RMS values of the voltage at the PCC, voltage drop at the resistance filter and at the inductance filter respectively.

At the same time, peak value of $V_{A B}$ is related to the modulation index $(m)$ and the DC-link voltage $\left(V_{D C \text {-LINK }}\right)$ by (4):

$$
m=\frac{\vec{V}_{A B}}{V_{D C-L I N K}} .
$$

If $m$ is expressed as (5) one has:

$$
m=\sqrt{2} \frac{\sqrt{\left(V_{\text {grid }}+I_{\text {grid }} R\right)^{2}+\left(w L I_{\text {grid }}\right)^{2}}}{V_{\text {DC- LINK }}},
$$

where $I_{\text {grid }}$ is the injected RMS reference current and $V_{D C \text {-LINK }}$ is the measured DC-link voltage. Thus, the modulation index $m$ has been calculated to obtain the desired amplitude of $\vec{V}_{A B}$ according to the phasor diagram in Fig.2(b).

To calculate the angle $(\alpha)$ of $\vec{V}_{A B}$, a unitary vector in the direction of such phasor is calculated as (5):

$$
\vec{u}_{\text {ref }}=\frac{\left(V_{\text {grid }}+I_{\text {grid }} R\right) \cdot \vec{u}_{d}+\left(w L I_{\text {grid }}\right) \cdot \vec{u}_{q}}{\sqrt{\left(V_{\text {grid }}+I_{\text {grid }} R\right)^{2}+\left(w L I_{\text {grid }}\right)^{2}}} .
$$

Thus, the reference voltage $\vec{V}_{A B}$ is generated and it will be used in the shoot-through sinusoidal pulse width modulation with the properly $\mathrm{m}$ and its phase $\vec{u}_{r e f}$.

\section{Modulation Technique}

There are two kinds of switching signals to generate separately in the 3L-NPC qZSI connected to the electrical grid. On one hand it is necessary to generate the normal switching signals $\left(S_{i, n}\right)$ in order to track the reference signal which is obtained as explained in section III. On the other hand the shoot-though states $\left(S_{t}\right)$ must to be added carefully in order to boost the input voltage $\left(V_{I N}\right)$.

Some requirements are demanded when shoot-through states are generated, for instance do not affect to the average output voltage and they have to be uniformly distributed during the whole output voltage period with constant width. These features produce several advantages such as minimum ripple of the input current, minimum value of the passive elements, reduction the THD of the output voltage and allow obtaining the desired boost factor. 


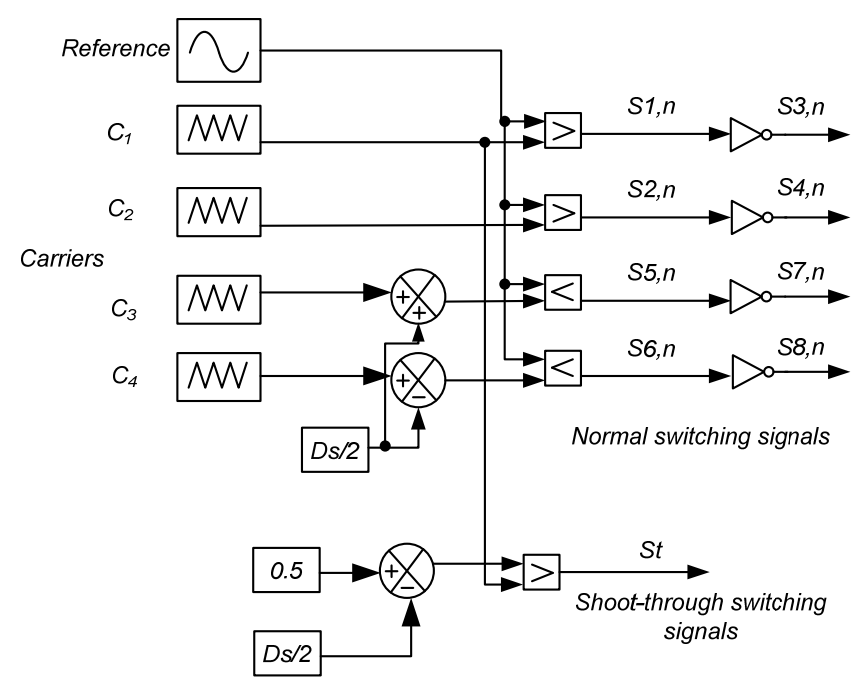

Fig. 1. Implementation sketch of the modulation technique.

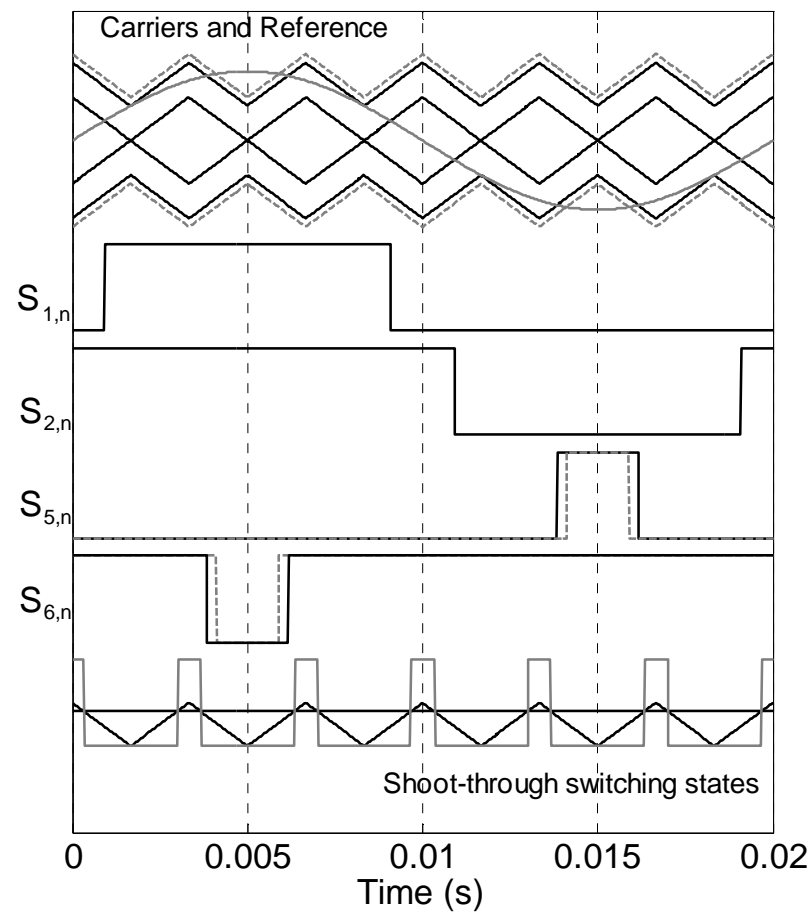

Fig. 4. Normal and shoot-through switching states.

In this work the modulation technique proposed in [15] has been used to achieve the aforementioned features. Fig. 3 shows the implementation of this modulation technique.

In Fig.4 normal switching states and shoot-through states are displayed.

\section{V.SIMULATION RESULTS}

In order to validate the proposed control strategy to generate the reference voltage $\vec{V}_{A B}$ in the 3L-NPC qZSI and thus, to inject current into the grid in phase with $\vec{V}_{\text {grid }}$, a comprehensive simulation study was performed in PSCAD.

Power stage, control strategy and modulation technique have been implemented in this simulation tool and the obtained results in different situations are shown and discussed in the next points.
TABLE II

SIMULATION PARAMETERS

\begin{tabular}{|c|c|c|}
\hline Parameter & Unit & Value \\
\hline Inductors $L_{1}, L_{3}$ & $(\mathrm{mH})$ & 0.29 \\
\hline Inductors $L_{2}, L_{4}$ & $(\mathrm{mH})$ & 0.29 \\
\hline Capacitor $C_{1}, C_{4}$ & $(\mathrm{mF})$ & 4 \\
\hline Capacitor $C_{2}, C_{3}$ & $(\mathrm{mF})$ & 1.3 \\
\hline Vin & $(\mathrm{V})$ & 400 \\
\hline Vgrid & $(\mathrm{V})$ & 230 \\
\hline Igrid (reference) & $(\mathrm{A})$ & 20 \\
\hline$L_{\text {filter }}$ & $(\mathrm{mH})$ & 4 \\
\hline$D_{s}$ & For case 2 & 0.1 \\
\hline
\end{tabular}

\section{A. Case 1. Shoot-Through Duty Cycle Equal to Zero}

In order to realize a simpler case and focus on the proper synchronization of $\vec{I}_{\text {grid }}$ with $\vec{V}_{\text {grid }}$, the first case has been simulated with shoot-through duty cycle $\left(D_{s}\right)$ equal to zero. In Table II we can see the simulation parameters and in Fig. 5 the obtained results are depicted. Fig.5(a) shows the $v_{\text {grid }}(t)$ and $u_{d}(t)$ and their proper synchronization between signals. Fig.5(b) shows $v_{I N}(t)$ and $i_{I N}(t)$ in which pulsation at $100 \mathrm{~Hz}$ in input current can be appreciated due to the single phase power system. Fig.5(c) represents $v_{A B}(t)$. Finally, Fig.5(d), 5(e) and (f) show $m, v_{D C-L I N K}(t), v_{\text {grid }}(t)$ and $i_{\text {grid }}(t)$ respectively. Injected current in phase with voltage at the PCC with the desired RMS value is obtained.

\section{B. Case 2. With Shoot-Through Duty Cycle}

In this case shoot through switching states are added to the normal states in order to increase the input voltage. $D_{s}$ has to assured equation (7) [9]:

$$
D_{s} £ 1-m,
$$

therefore, added $D_{s}$ is equal to 0.1 .

Fig.6 shows the new simulation results. Fig.6(a) shows the $v_{\text {grid }}(t)$ and $u_{d}(t)$ and a proper synchronization between signals is obtain again. Fig.6(b) shows $v_{I N}(t)$ and $i_{I N}(t)$ in which the same pulsation at $100 \mathrm{~Hz}$ in input current can be appreciated. In Fig.6(c) represents $v_{A B}(t)$ that is going to zero during the whole period. Finally, Fig.6(d), (e) and (f) show $m$ (less than in case 1$), v_{D C \text {-LINK }}(t), v_{\text {grid }}(t)$ and $i_{\text {grid }}(t)$ respectively. $v_{D C \text { - }}$ LINK $(t)$ in this case drop to zero due to the shoot-through states during the whole period and also it has been boosted. Injected current in phase with voltage at the PCC with the desired RMS is obtained again.

\section{Control System to AdJust the $D_{s}$}

The voltage between terminals of an inductor is:

$$
v_{L}(t)=L \frac{d i_{L}(t)}{d t}
$$

where $v_{L}(t)$ is the instantaneous value of the voltage in the inductance, $L$ is the inductance value and $i_{L}(t)$ is the current across the inductance. 


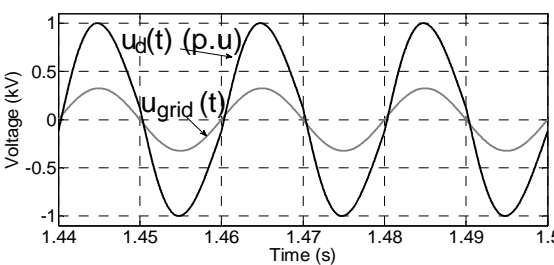

(a)

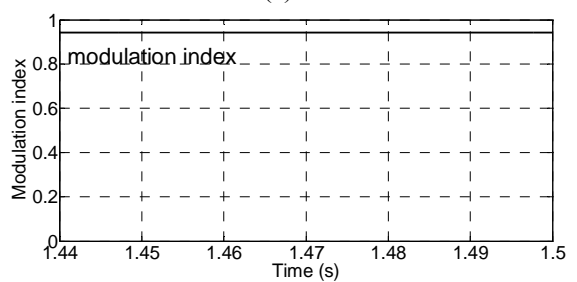

(b)

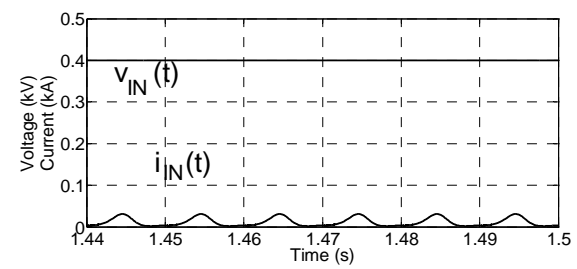

(c)

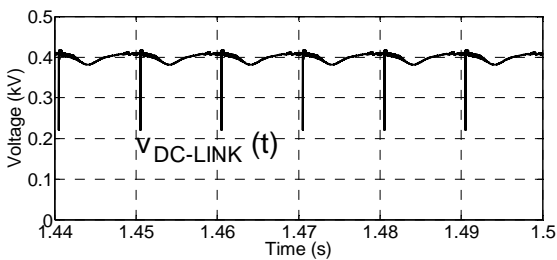

(d)

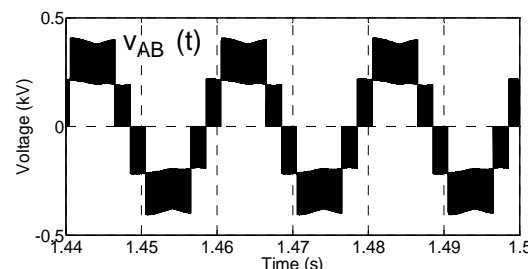

(e)

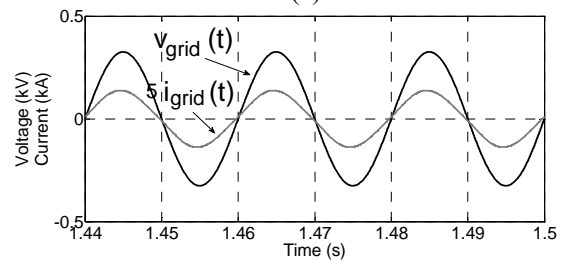

(f)

Fig.5. Results of simulation with shoot-through duty cycle equal to zero (case 1): (a) voltage at the PCC and unitary vector in $d$ axis, (b) modulation index of reference signal, (c) input current and voltage, (d) DC-link voltage, (e) output voltage before filter (between branches) and (f) injected current and grid voltage.

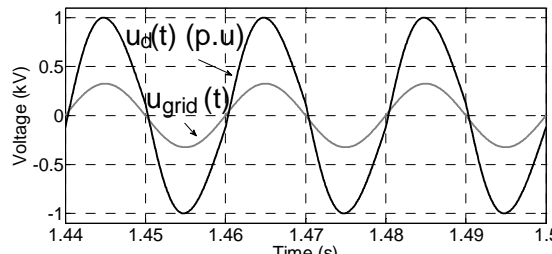

(a)

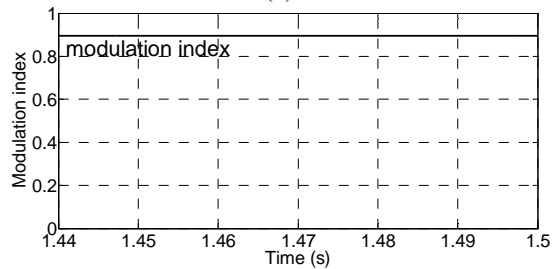

(b)

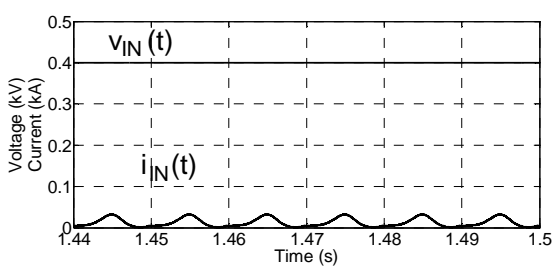

(c)

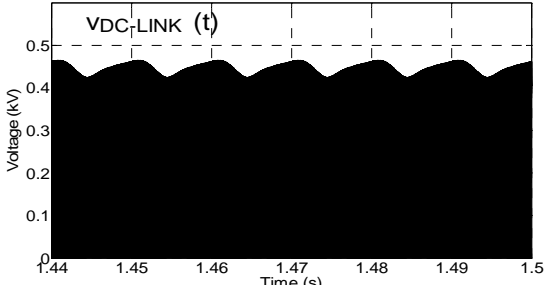

(d)

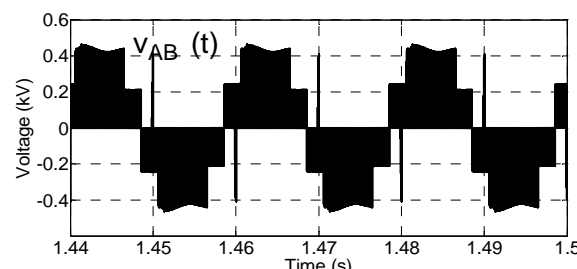

(e)

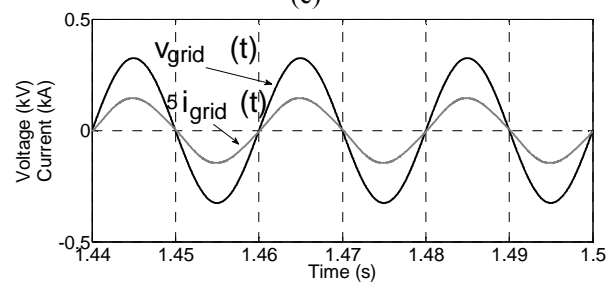

(f)

Fig.6. Results of simulation with shoot-through duty cycle (case 2): (a) voltage at the PCC and unitary vector in $d$ axis when shoot-through duty cycle is generated, (b) modulation index of reference signal, (c) input current and voltage, (d) DC-link voltage, (e) output voltage before filter (between branches) and (f) injected current and grid voltage.

In our case, according to the equivalent scheme in Fig.2(a) it also can be obtained as (9):

$$
v_{L}(t)=v_{A B}(t)-v_{\text {grid }}(t)
$$

where $v_{A B}(t)$ is the instantaneous voltage between branches and $v_{\text {grid }}(t)$ is the grid voltage.

In order to assure the control in the inductance and be able to inject the desired current for every value of $v_{\text {grid }}(t)$, equation (10) must be satisfied:

$$
V_{D C-\text { LINK }}>\sqrt{2} V_{\text {grid }} \text {. }
$$

In the 3L-NPC qZSI, expression (10) could be expressed as (12) taking into the account equation (11) [17]:

$$
\begin{gathered}
V_{D C-\text { LINK }}=\frac{V_{I N}}{1-2 D_{S}}, \\
\frac{V_{I N}}{1-2 D_{S}}>\sqrt{2} V_{\text {grid }} .
\end{gathered}
$$

Operating with equation (12) we can obtain expression (13):

$$
D_{S}>\frac{1}{2}-\frac{V_{I N}}{2 \sqrt{2} V_{\text {grid }}},
$$

which assures that the injected current control can be carried out successfully.

In order to validate the proposed way to calculate the minimum value of $D_{s}$, two cases where $V_{I N}$ is less than peak value of $V_{\text {grid }}$ have been made. In one of them, $D_{s}$ is equal to zero and the other one, $V_{I N}$ will be boosted with $D_{S}$ is distinct to zero. $V_{\text {in }}$ in both cases is equal to $315 \mathrm{~V}$ (less than $\sqrt{2} V_{\text {grid }}$ ).

\section{A. Case 1. $V_{I N}$ Less than Peak Value of $V_{\text {grid }}$ and Shoot-} Through Duty Cycle Equal to Zero

In this case where $V_{I N}$ is less than the peak value of $V_{\text {grid }}$ and $D s$ is equal to zero, the obtained results for the injected current and voltage at the PCC are shown in Fig.7.

We can see how the injected current cannot achieve the reference peak value $(\sqrt{2} 20 \mathrm{~A})$ due to the voltage $V_{D C \text {-LINK }}$ is not enough and as consequence the control in the inductance is not made properly. This situation can be observed in Fig.8, where $m$ is greater than one. 


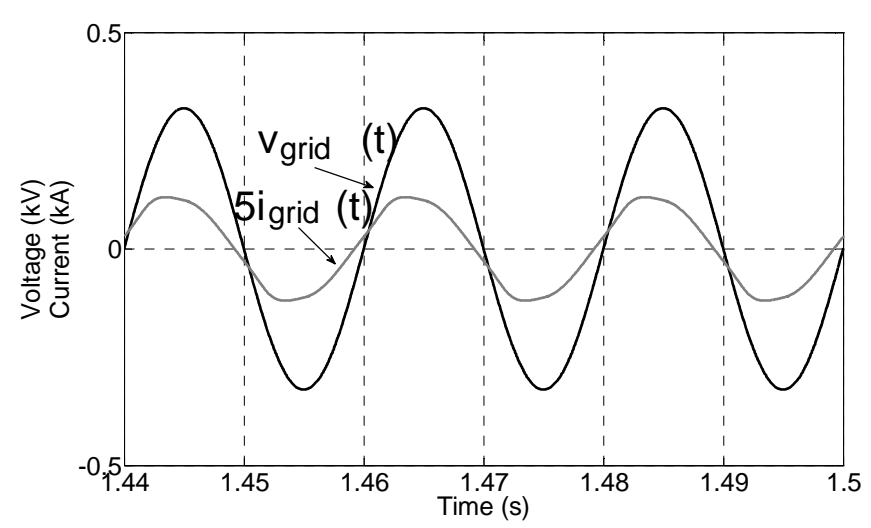

Fig.7. Injected current and grid voltage.

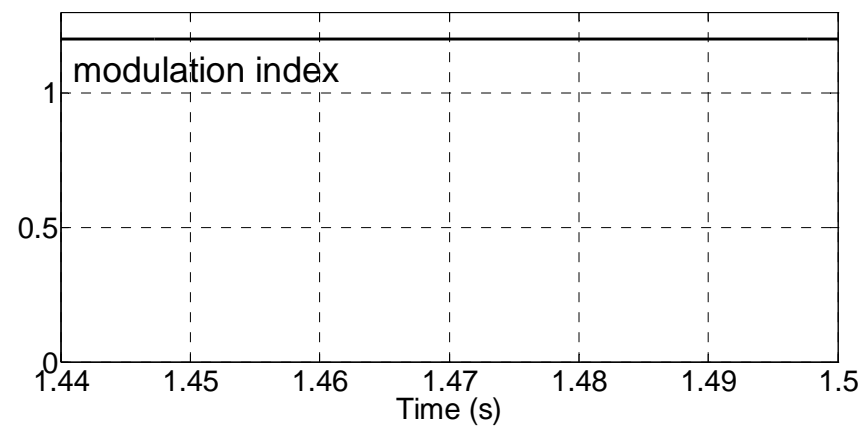

Fig.8. Modulation index.

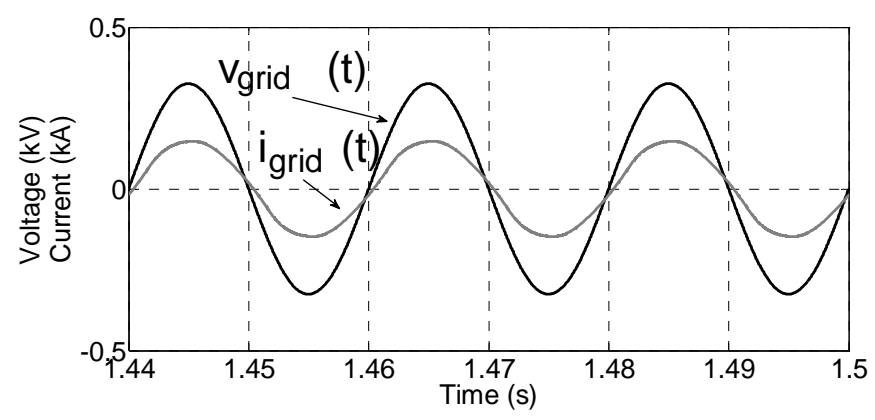

Fig.9. Injected current and grid voltage.

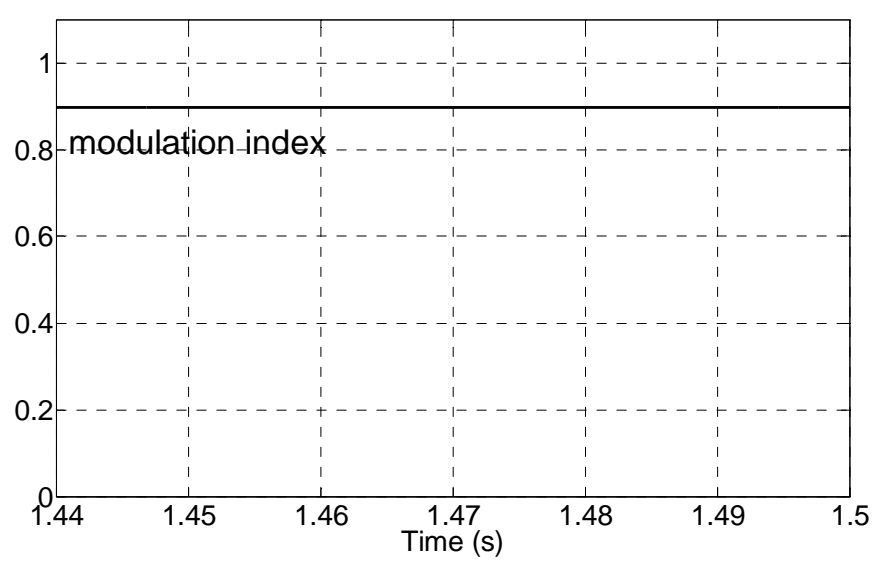

Fig.10. Modulation index.
B. Case 2. $V_{I N}$ Less than Peak Value of $V_{\text {grid }}$ and ShootThrough Duty Cycle Distinct to Zero

In this case, $V_{I N}$ is boosted with $D_{s}$ equal to 0.15 . The obtained results for the injected current and voltage at the PCC are depicted in Fig.9.

We can see how in this case, the injected current has the desired peak value because the control has been possible properly. This fact is shown in Fig.10, where $m$ is less than one.

\section{CONCLUSIONS}

In this paper, a single-phase 3L-NPC qZSI connected to the grid has been analyzed. A control strategy to inject current synchronized in phase with the voltage at the PCC has been explained. It is carried out by means of controlling $V_{a b}$. It has been tested with and without shoot-through switching states.

Finally, a method to calculate the minimum value of $D_{s}$ that assures the proper control of the injected current has been proposed and validated in simulations when $V_{I N}$ is less than the peak value of $V_{\text {grid. }}$. It is an important situation, in which $3 \mathrm{~L}-$ NPC qZSI due to its possibility of boosting input voltage is better than the traditional inverter.

\section{ACKNOWLEDGMENT}

The authors would like to thank to the Spanish institutions "Ministerio de Economía y Competitividad", "Junta de Extremadura" and "Fondos FEDER" for its support in this research.

\section{REFERENCES}

[1] F. Gao, P. C. Loh, F. Blaabjerg, D. M. Vilathgamuwa, "Dual Z-source inverter with three-level reduced common-mode switching", IEEE Transactions on industry applications, vol.43, no. 6, pp.1597-1608, 2007.

[2] P. C. Loh, S. W. Lim, F. Gao, F. Blaabjerg, "Three-level Z-source inverters using a single LC impedance network", IEEE Transactions on power electronics, vol. 22, no. 2, pp. 706-711, 2007.

[3] Anderson, J.; Peng, F.Z., "Four quasi-Z-Source inverters", in Proc. of IEEE Power Electronics Specialists Conference PESC'2008, pp. 27432749, June 15-19, 2008.

[4] D. Vinnikov, I. Roasto, "Quasi-Z-Source-Based Isolated DC/DC Converters for Distributed Power Generation," IEEE Trans. Ind. Electron., vol.58, no.1, pp.192-201, Jan. 2011.

[5] Dong Cao, Shuai Jiang, F. Z. Peng, "Low-Cost Semi-Z-source Inverter for Single-Phase Photovoltaic Systems," IEEE Trans. Power Electron., vol. 26, no. 12, pp. 3514-3523, 2011.

[6] F. Li, B. Ge, D. Sun; D. Bi, F. Z Peng; A. R. Haitham, "Quasi-Z source inverter with battery based PV power generation system," Electrical Machines and Systems (ICEMS), 2011 International Conference on , vol., no., pp.1-5, 20-23 Aug. 2011.

[7] Y. Li, J. Anderson, F. Z. Peng, D. Liu, "Quasi-Z-Source Inverter for Photovoltaic Power Generation Systems," Applied Power Electronics Conference and Exposition, 2009. APEC 2009. Twenty-Fourth Annual IEEE, vol., no., pp.918-924, 15-19 Feb. 2009.

[8] J. Zakis, D. Vinnikov, "Study of Simple MPPT Converter Topologies for Grid Integration of Photovoltaic Systems," Scientific Journal of RTU. 4. series., Energétika un elektrotehnika. - 29. vol. (2011), pp 6772 .

[9] T. W. Chun, H. H. Lee, H. G. Kim, E. C. Nho, "Power Control for a PV Generation System Using a Single-Phase Grid-Connected Quasi ZSource Inverter," IEEE Energy Conversion Congress \& Exposition, 8th International Conference on Power Electronics - ECCE, pp. 889-893, May 30-June 3, 2011. 
[10] J.H Park, H.G. Kim, E.C. Nho; T.W. Chun, "Capacitor voltage control for MPPT range expansion and efficiency improvement of gridconnected Quasi Z-Source Inverter," Power Electronics Conference (IPEC), 2010 International , vol., no., pp.927-931, 21-24 June 2010.

[11] J. Liu; S. Jiang, D. Cao, Xi Lu, F. Z. Peng, "Sliding-mode control of quasi-Z-source inverter with battery for renewable energy system," Energy Conversion Congress and Exposition (ECCE), 2011 IEEE , vol., no., pp.3665-3671, 17-22 Sept. 2011.

[12] Ott, S., Roasto, I., Vinnikov, D., Lehtla, T.: Analytical and Experimenta Investigation of Neutral Point Clamped Quasi-Impedance-Source Inverter. Scientific Journal of Riga Technical University, Power and Electrical Engineering, vol.29, pp.113-118 (2011).

[13] Stepenko, S., Husev, O., Vinnikov, D., Ivanets, S.: FPGA Control of the Neutral Point Clamped Quasi-Z-Source Inverter. 13th Biennial Baltic Electronics Conference, pp.263-266 (2012).

[14] Husev, O., Roncero-Clemente, C., Stepenko, S., Vinnikov, D., RomeroCadaval, E.: CCM Operation Analysis of the Single-Phase Three-Leve Quasi-Z-Source Inverter. The 15th International Power Electronics and Motion Control Conference and Exposition EPE-PEMC 2012 ECCE Europe, pp.DS1b.21-1-DS1b.21-6 (2012).

[15] Roncero-Clemente, C., Romero-Cadaval, E., Husev, O., Vinnikov, D.: Simulation Study of Different Modulation Techniques for Three-Level Quasi-Z-Source Inverter. Scientific Journal of Riga Technical University, Power and Electrical Engineering. (2012).

[16] PSCAD/EMTDC User's Guide. Manitoba HVDC Research Center, (2005).

[17] Oleksandr Husev, Sergey Stepenko, Carlos Roncero Clemente, Enrique Romero Cadaval, Dmitri Vinnikov. "Single Phase Three-Level QuasiZ-Source Inverter With a New Boost Modulation Technique". 38th Annual Conference of the IEEE Industrial Electronics Society, IECON 2012. Conference Proceeding, pp. 5856- 5861. Montréal, Canada October 2012.

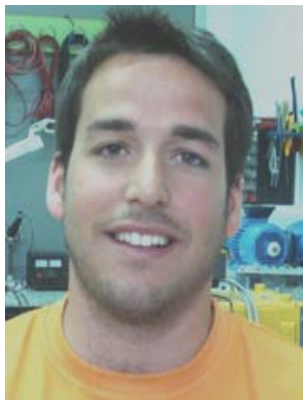

Carlos Roncero-Clemente (S'08) received the B.Sc. and M.Sc. degrees in electrical engineering from University of Extremadura, Spain, in 2006 and 2008, respectively, where he is currently working toward the Ph.D. degree. His Ph.D. thesis is devoted to the research and development of controls for inverters. $\mathrm{He}$ is currently with the Power Electrical and Electronic Systems (PE\&ES) Research Group (http://peandes.unex.es). His research interests are power electronics in the power system, power quality, active power filters, renewable energy sources control, and smart grid.

Postal address: Universidad de Extremadura, Campus universitario, Escuela de Ingenierías Industriales, Laboratorio C2.7, Avda. de Elvas, s/n 06006, Badajoz, Spain

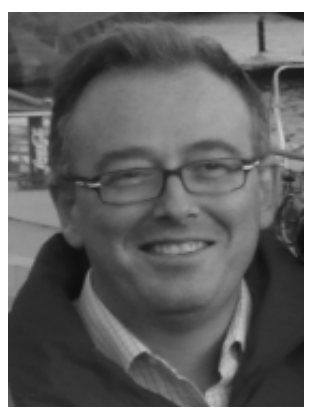

Enrique Romero-Cadaval (SM'10) was born in Villafranca de los Barros, Badajoz, Spain, in 1968. He received the M.Sc. degree in electronic industrial engineering from ICAI, Universidad Pontificia de Comillas, Madrid, Spain, in 1992 and the $\mathrm{Ph}$. D. degree from the Universidad de Extremadura, Badajoz, Spain, in 2004. He is a full Professor in power electronics at the Universidad of Extremadura, Badajoz, Spain. He is currently with the Power Electrical and Electronic Systems (PE\&ES) Research Group (http://peandes.unex.es). His research interests are power electronics in the power system, power quality, active power filters, renewable energy sources control, smart grids, and electrical vehicles.

Postal address: Universidad de Extremadura, Campus universitario, Escuela de Ingenierías Industriales, Laboratorio C2.7, Avda. de Elvas, s/n 06006, Badajoz, Spain.

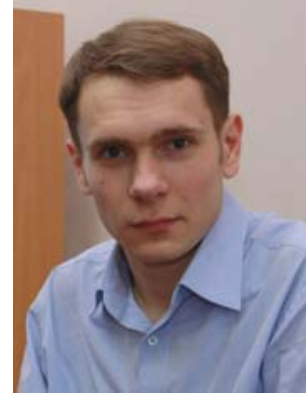

Oleksandr Husev received the B.Sc., M.Sc. in industrial electronics and the Ph.D. degrees from Chernihiv State Technological University, Chernihiv, Ukraine, in 2007, 2008 and 2012 respectively. He is an assistant of the Department of Industrial Electronics, Chernihiv State Technological University and currently cooperates with the Department of Electrical Engineering, Tallinn University of Technology. He has over 20 publications and is the holder of several patents.

His research interests are in control systems for power electronic converters based on a wide range of algorithms, including modeling, design, and simulation.

Postal address: Chernihiv State Technological University, Shevchenko street 95, Chernihiv 14027, Ukraine.

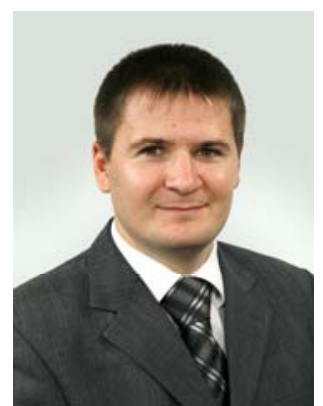

Dmitri Vinnikov received the Dipl.Eng, M.Sc. and Dr.Sc.techn. degrees in electrical engineering from Tallinn University of Technology, Tallinn, Estonia, in 1999, 2001 and 2005 , respectively.

$\mathrm{He}$ is presently a Senior Researcher in the Department of Electrical Engineering, Tallinn University of Technology. He has authored more than 100 published papers on power converters design and development and is the holder of several Utility Models in this application field. His research interests include switch mode power converters, modeling and simulation of power systems, applied design of power converters and control systems and application, and development of energy storage systems.

Postal address: Department of Electrical Engineering, Tallinn University of Technology, Ehitajate tee 5, 19086 Tallinn, Estonia.

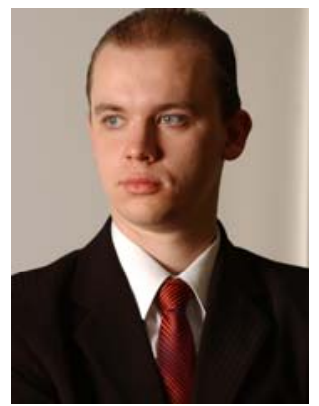

Serhii Stepenko received the B.Sc. and M.Sc. degrees in electronics from Chernihiv State Technological University, Chernihiv, Ukraine, in 2010 and 2011 respectively, where he is currently working toward the $\mathrm{PhD}$ degree. His $\mathrm{PhD}$ thesis is devoted to intelligent regulation in energy efficient voltage converters.

$\mathrm{He}$ is an assistant at the Department of Industrial Electronics, Chernihiv State Technological University and currently cooperates with the Department of Electrical Engineering, Tallinn University of Technology. He has 16 publications including papers in the international conferences proceedings, Ukrainian scientific journals and articles indexed by IEEE Xplore, Scopus and Google Scholar databases.

His research interests are in power electronics, intelligent regulation and electrical systems based on renewable energy sources.

Postal address: Chernihiv State Technological University, Shevchenko street 95, Chernihiv 14027, Ukraine. 